ORIGINAL ARTICLE

\title{
Prevalence of respiratory symptoms in sheep breeders
}

\author{
K Radon, C Winter
}

Occup Environ Med 2003;60:770-773

See end of article for authors' affiliations ......................

Correspondence to: Dr K Radon, Institute of Occupational and Environmental Medicine, Ludwig-MaximiliansUniversity Munich, Ziemssenstr. 1, D-80336

Munich, Germany; Katja.Radon@arbeits. med.uni-muenchen.de

Accepted

7 November 2002
Background: The European Farmers' Study has indicated that sheep farmers might be at risk for the development of respiratory symptoms.

Aims: To assess the prevalence of respiratory symptoms in sheep breeders and potential work related risk factors.

Methods: All sheep breeders listed in two regions of South Germany were asked to answer a mailed questionnaire on respiratory symptoms, work related respiratory symptoms (WRS), and details of farming. Overall, 325 sheep breeders keeping at least 10 sheep could be included in the survey (response rate 81.9\%). The prevalences were compared to the results of the European Farmers' Study.

Results: Sheep breeders showed a significantly higher prevalence of asthma related symptoms (prevalence odds ratio (POR) 2.1, 95\% Cl 1.5 to 3.0), chronic phlegm (POR 4.0, 95\% Cl 2.8 to 5.9), and WRS (POR $1.7,95 \% \mathrm{Cl} 1.3$ to 2.2 ) after adjusting for age, gender, smoking habits, full time farming, and study centre. In the multiple logistic regression model the risk for asthma related symptoms was doubled in full time farmers (POR 2.3, 95\% Cl 1.2 to 4.3). The major predictor of WRS was full time farming (POR 1.6, $95 \% \mathrm{Cl} 0.93$ to 2.7) and the use of chemical footbaths (POR 2.1, 95\% Cl 1.2 to 3.7 ).

Conclusions: Sheep breeders might be at high risk for the development of respiratory symptoms. These symptoms may be associated with work intensity and chemical exposure during work. Studies including objective measurements should be performed.
A nimal farmers are known to be at high risk for respiratory symptoms and diseases. ${ }^{1-4}$ Most studies focus on pig, ${ }^{5-11}$ dairy, ${ }^{12-14}$ or poultry farmers. ${ }^{1516}$ However, some surveys indicated an increased risk of respiratory symptoms in sheep farmers. ${ }^{17-19}$

There are several exposures that might prove to be risk factors for the respiratory health of sheep farmers. If sheep are kept outside precipitation may cause proliferation of bacteria in the skin-fleece microenvironment. This may discolour the fleece and cause a dermatitic condition called "fleece-rot". ${ }^{20}{ }^{21}$ Therefore, many sheep farmers dip the sheep in insecticide showers. ${ }^{22}{ }^{23}$ Additionally, the hoof horn of sheep may also be affected by bacteria causing foot-rot. ${ }^{24}$ To treat infestation of bacteria in the hooves, footbaths containing chemicals such as formaldehyde are used. During the lambing season sheep farmers often stay inside the sheep barn most part of the day and might thus be exposed to high levels of organic dust. Since Gram negative bacteria (Pseudomonas spp.) are found in the fleece, ${ }^{20}$ exposure to endotoxins might be increased.

Therefore, the aim of the study was to determine the prevalence of chronic and work related respiratory symptoms in sheep farmers compared to animal farmers participating in the European Farmers' Study. ${ }^{1}$ Additionally, potential farming related risk factors for respiratory symptoms were explored.

\section{MATERIAL AND METHODS}

Study population

In order to focus on subjects predominantly keeping exclusively sheep, our target population were sheep breeders rearing at least 10 sheep in Bavaria and Baden-Wuerttemberg (South Germany). All sheep breeders $(\mathrm{n}=450)$ in these areas were contacted by mail between September 2000 and July 2001 and asked to fill in a paper questionnaire. Following the first letter up to two reminders were sent.

\section{Questionnaire}

The first part of the questionnaire was taken from the questionnaire of the European Farmers' Study. ${ }^{1}$ For participants whose main job was not farming, one item on the current main job was included. ${ }^{25}$ The second part of the questionnaire contained 12 items on details of sheep rearing that might prove to be risk factors for respiratory symptoms. Some of these items were taken from our previous study on farmers in Schleswig-Holstein ${ }^{14}$ and supplemented in collaboration with specialists on sheep rearing of the local sheep farmers' association (Landesverband Bayerischer Schafhalter). The items included:

- Detailed assessment of the mode of operation

- Number of sheep in three categories: 10-50, 50-500, >500 sheep

- Sheep shearing performed by the sheep breeder as a binary variable

- Use of insecticide showers and type of insecticide showers used

- Use of chemical footbaths and type of chemical footbaths used (formaldehyde, copper sulphate, others)

- Time daily spent inside a barn: (a) during lambing season; (b) outside the lambing season.

\section{Analysis}

For those participants whose principal job was not farming, the main job reported by the participants was coded according to the European Community socioeconomic status group classification. ${ }^{3}$ Asthma related symptoms (ARS) were defined as wheezing, awakening by shortness of breath, and/

Abbreviations: AIC, Akaike Information Criteria; ARS, asthma related symptoms; ODTS, organic dust toxic syndrome; POR, prevalence odds ratio; WRS, work related respiratory symptoms 
Main messages

- An increased risk of general and work related respiratory symptoms has been observed in sheep breeders.

- Full time farmers were most likely to report respiratory symptoms.

- The use of chemical footbaths might represent a risk factor for work related respiratory symptoms in sheep breeders.

or an attack of asthma during the past 12 months. Phlegm on most days for at least three months during the preceding year was referred to as chronic phlegm. Wheezing, shortness of breath, cough, and/or cough with phlegm during work were categorised as work related respiratory symptoms (WRS). Since the daily duration of work inside the sheep barn in general as well as during the lambing season was skewed to the right the logarithm of the daily duration of work inside the animal barn +1 was used for analyses.

The prevalence of respiratory symptoms was compared to the prevalence in the population of the European Farmers' Study not keeping sheep using multiple logistic regression analysis. The design of this study on European farmers ${ }^{1}$ was comparable to the present study and identical survey instruments have been used. Therefore, we were able to compare the results of the study to our present survey. All models were adjusted for age, gender, smoking habits, full time farming, and study centre.

Potential risk factors for respiratory symptoms were evaluated using multiple logistic regression adjusting for age, gender, and smoking. For each symptom a final logistic regression model was developed, additionally adjusting for nasal allergies as potential confounder. The Akaike Information Criteria (AIC) were used to select the best final model for each group of symptoms. ${ }^{26}$ All analyses were performed with the SAS software package (SAS Institute, Inc., Cary, NC, USA).

\section{RESULTS}

\section{Subjects}

Overall, 345 sheep breeders answered the questionnaire. After removing those who had moved out of the area

Table 1 Descriptive data

\begin{tabular}{ll}
\hline & $\mathbf{n}(\%)$ \\
\hline Age (years), mean (SD) [range] & $49.7(11.4)$ [18-78] \\
Number & 325 \\
Male gender & $275(85.1)$ \\
Current smokers & $45(13.9)$ \\
Ex-smokers & $84(26.0)$ \\
Part time farming & $202(62.3)$ \\
Main job ( $\mathrm{n}=179):$ & \\
Clerical work & $73(40.8)$ \\
Metal workers & $18(10.1)$ \\
Construction, mining & $18(10.1)$ \\
Family managers, retired & $38(21.2)$ \\
Others & $32(17.9)$ \\
Work inside confinement house & $309(95.1)$ \\
12 months prevalence of respiratory symptoms & \\
Asthma related symptoms (ARS) & $68(20.9)$ \\
Chronic phlegm & $57(17.7)$ \\
Nasal allergy & $54(16.7)$ \\
Work related respiratory symptoms (WRS) & $124(38.4)$ \\
Lifetime prevalence of flu-like illness (ODTS) & $74(23.1)$ \\
\hline
\end{tabular}

\section{Policy implications}

- The increased risk of respiratory symptoms needs to be confirmed in full time sheep farmers, including objective measurements of exposure and outcome.

- Sheep breeders might be encouraged to reduce the use of formaldehyde.

( $\mathrm{n}=14)$, those who were no longer keeping sheep $(\mathrm{n}=10)$, and those who had died $(\mathrm{n}=5)$ from the sampling frame $(n=421)$, the overall response rate was $81.9 \%$. Restricting the analyses to respondents keeping at least 10 sheep, 325 active sheep breeders could be included.

Table 1 gives the descriptive data of the study population. The majority of participants were male $(86 \%)$, with a mean age of 49.9 (SD 11.5) years. For only $38 \%$ of the sheep breeders was farming considered the main job. Part time sheep breeders reported primarily clerical work (41\%), family managing or being retired $(21 \%)$, metal work $(10 \%)$, and construction $(10 \%)$ as their main job.

\section{Prevalence of respiratory symptoms}

Table 1 shows the 12 months prevalence of chronic respiratory symptoms. In addition to the high prevalence of ARS $(20.9 \%), 16.7 \%$ of the participants reported nasal allergies. Regarding the prevalence of WRS, almost $40 \%$ of the farmers reported wheezing, shortness of breath, and/or cough during work. The lifetime prevalence of flu-like illness suggesting organic dust toxic syndrome (ODTS) was $23 \%$.

Comparing these prevalences to the participants of the European Farmers' Study not keeping sheep (fig 1), sheep breeders reported general respiratory symptoms significantly more often as well as respiratory symptoms during work. These differences were most pronounced for chronic phlegm (prevalence odds ratio (POR) 4.0, 95\% confidence interval (CI) 2.8 to 5.9 ) and flu-like illness (POR 4.7, 95\% CI 3.3 to 6.6).

\section{Farming characteristics and respiratory symptoms}

Table 2 shows the associations between farming characteristics and respiratory symptoms after adjusting for age, gender, and smoking. Because the variable "shepherd" was redundant with gender, no model for shepherds could be carried out. Working full time as a farmer, keeping more than 500 sheep, and grain production turned out as the major

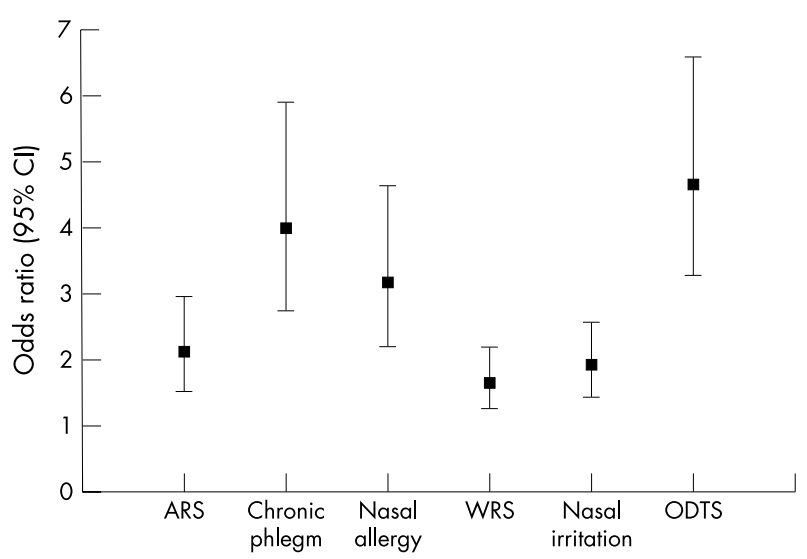

Figure 1 Odds ratios $(95 \% \mathrm{Cl})$ of respiratory symptoms for sheep breeders ( $\mathrm{n}=325$ ) compared to farmers of the European Farmers' Study ( $\mathrm{n}=6950)$. Odds ratios adjusted by age, gender, smoking habits, full time farming, and study centre. 
Table 2 Distribution of farm characteristics and univariate associations between farming characteristics and the prevalence of respiratory symptoms $(n=325)$

\begin{tabular}{|c|c|c|c|c|c|}
\hline & \multirow[b]{2}{*}{ n (\%) } & \multicolumn{4}{|l|}{ POR $(95 \% \mathrm{Cl})^{*}$} \\
\hline & & ARS & Chronic phlegm & WRSt & ODTS \\
\hline \multicolumn{6}{|l|}{ Main job } \\
\hline No & $202(62.4)$ & 1 & 1 & 1 & 1 \\
\hline Yes & $122(37.7)$ & $2.5(1.4$ to 4.4$)$ & $2.7(1.4$ to 5.0$)$ & $1.9(1.2$ to 3.1$)$ & $1.9(1.1$ to 3.2$)$ \\
\hline \multicolumn{6}{|l|}{ Sheep and other animals } \\
\hline No & $203(62.5)$ & 1 & 1 & 1 & 1 \\
\hline Yes & $122(37.5)$ & $0.96(0.54$ to 1.7$)$ & $1.4(0.7$ to 2.5$)$ & $0.92(0.57$ to 1.5$)$ & $0.88(0.51$ to 1.5$)$ \\
\hline \multicolumn{6}{|l|}{ Grain production } \\
\hline No & $235(72.3)$ & 1 & 1 & 1 & 1 \\
\hline Yes & $90(27.7)$ & $1.8(0.95$ to 3.3$)$ & $2.6(1.3$ to 5.1$)$ & $1.0(0.61$ to 1.8$)$ & $1.5(0.8$ to 2.6$)$ \\
\hline \multicolumn{6}{|l|}{ Number of sheep } \\
\hline 10 to 50 & $166(51.9)$ & 1 & 1 & 1 & 1 \\
\hline 50 to 500 & $127(39.7)$ & $1.5(0.78$ to 2.7$)$ & $1.8(0.89$ to 3.6$)$ & $1.0(0.61$ to 1.7$)$ & 1.6 (0.87 to 2.8$)$ \\
\hline$>500$ & $27(8.4)$ & $2.7(1.0$ to 6.9$)$ & $3.7(1.3$ to 10.3$)$ & $2.2(0.94$ to 5.4$)$ & $2.3(0.92$ to 5.9$)$ \\
\hline \multicolumn{6}{|l|}{ Sheep shearing } \\
\hline No & $240(75.7)$ & 1 & 1 & 1 & 1 \\
\hline Yes & $77(24.3)$ & $1.7(0.90$ to 3.1$)$ & $1.1(0.56$ to 2.4$)$ & $1.3(0.77$ to 2.3$)$ & $1.2(0.62$ to 2.2$)$ \\
\hline \multicolumn{6}{|l|}{ Use of sheep dip } \\
\hline No & $233(72.8)$ & 1 & 1 & 1 & 1 \\
\hline Yes & $87(27.2)$ & $1.3(0.72$ to 2.4$)$ & $1.3(0.63$ to 2.5$)$ & $1.4(0.85$ to 2.4$)$ & $1.3(0.75$ to 2.4$)$ \\
\hline \multicolumn{6}{|l|}{ Use of chemical footbaths } \\
\hline No & $111(34.2)$ & 1 & 1 & 1 & 1 \\
\hline \multirow[t]{2}{*}{ Yes } & $214(65.9)$ & $1.5(0.79$ to 2.7$)$ & $1.3(0.65$ to 2.6$)$ & $2.3(1.4$ to 3.9$)$ & 3.5 (1.7 to 7.0$)$ \\
\hline & Mean (SD) & \multicolumn{4}{|c|}{ POR per $\log (\text { hour }+1)^{*}$} \\
\hline $\begin{array}{l}\text { Work in sheep barns during lambing season } \\
\text { (hours/day) }\end{array}$ & $3.5(3.1)$ & $1.7(0.49$ to 5.6$)$ & $3.3(0.83$ to 12.9$)$ & $1.8(0.65$ to 5.1$)$ & $1.7(0.53$ to 5.3$)$ \\
\hline Work in sheep barns (hours/day) & $1.7(1.8)$ & $3.2(0.9$ to 11.0$)$ & $1.9(0.44$ to 7.9$)$ & $2.3(0.78$ to 6.8$)$ & $2.3(0.67$ to 7.7$)$ \\
\hline
\end{tabular}

predictors for ARS. Similar associations were found for chronic phlegm. The main predictor for WRS in these analyses was use of chemical footbaths (POR 2.3, 95\% CI 1.4 to 3.9). Full time farming (POR 1.9, 95\% CI 1.1 to 3.2 ) and use of chemical footbaths (POR 3.5, 95\% CI 1.7 to 7.0 ) were significantly associated with symptoms of organic dust toxic syndrome.

These associations were also confirmed in the final multiple logistic regression model (table 3 ). In these models the odds of ARS of full time farmers was 2.3 -fold (95\% CI 1.2 to 4.3 ) increased compared to part time farmers. A similar association was seen for chronic phlegm $(1.9,95 \%$ CI 0.9 to $3.9)$. Grain crop was an even stronger predictor for chronic phlegm $(2.1,95 \%$ CI 1.0 to 4.3$)$. The use of chemical footbaths $(2.1,95 \%$ CI 1.2 to 3.7$)$ was a significant predictor of WRS.

\section{DISCUSSION}

In this first questionnaire survey including 325 sheep breeders the prevalence of respiratory symptoms and potential farming related risk factors for these symptoms have been assessed. A significantly increased odds ratio for general and work related respiratory symptoms was shown. After adjusting for potential confounding variables, work intensity and use of chemical footbaths emerged as the most important risk factor for respiratory symptoms.

In our study we were able to obtain a high response rate and we could include a comparably large number of sheep breeders. In view of the fact that our list of sheep breeders is expected to be complete, selection bias could be reduced as far as possible. However, since we were only able to include sheep breeders our results cannot be generalised to sheep farmers. Our detailed questionnaire instrument included validated questions on respiratory symptoms and took several potential confounding variables into account. No objective measurements of disease status could be performed. The European Community Respiratory Health Survey has shown that the item used to assess respiratory symptoms is a valid measure of disease status. ${ }^{27}$ Likewise, measurement of exposure (endotoxin, dust, exposure to chemicals) could not be performed in this survey. However, farm characteristics are considered to remain stable for some time, and therefore the use of questionnaire data to assess farming methods is thought to be a good proxy for exposure during

Table 3 Multiple logistic regression analysis of respiratory symptoms as dependent variables and characteristics of farm work as predictor variables

\begin{tabular}{|c|c|c|c|c|}
\hline \multirow[b]{2}{*}{ All sheep breeders $(n=309)$} & \multicolumn{4}{|l|}{ POR $(95 \% \mathrm{Cl})^{*}$} \\
\hline & ARS & Chronic phlegm & WRSt & ODTS \\
\hline Main job & $2.3(1.2$ to 4.3$)$ & $1.9(0.94$ to 3.9$)$ & $1.6(0.93$ to 2.7$)$ & $1.5(0.80$ to 2.7$)$ \\
\hline Grain crop & - & 2.1 (1.0 to 4.3$)$ & - & \\
\hline$>500$ sheep & $1.2(0.44$ to 3.3$)$ & $1.4(0.48$ to 4.0$)$ & $1.3(0.52$ to 3.4$)$ & $1.2(0.45$ to 3.3$)$ \\
\hline Use of chemical footbaths & - & - & 2.1 (1.2 to 3.7$)$ & $3.0(1.5$ to 6.2$)$ \\
\hline
\end{tabular}

*Adjusted for age, gender, smoking habits, nasal allergies.

tWRS, work related respiratory symptoms (shortness of breath, cough, cough with phlegm, and/or wheezing during work). 
the preceding months. ${ }^{11}{ }^{28}$ Nevertheless, in the follow up of this survey objective measurements of disease status and exposure should be included to confirm our results.

Overall, the prevalence of asthma related symptoms as well as respiratory symptoms during work found in this population was significantly higher than in the European Farmers' Study. Our results were confirmed by a recent study in New Zealand farmers ${ }^{17}$ showing a significantly increased prevalence of breathing problems at work in sheep farmers. Additionally, the well known association between exposure to grain dust and the development of symptoms of chronic bronchitis ${ }^{17} 29$ was shown in the present survey, confirming the validity of our results. A comparison of the results for sheep farmers in the age range $20-44$ years with data from the general population ${ }^{30}$ revealed a significantly higher prevalence of chronic phlegm for sheep farmers. However, the prevalence of asthma and allergies was comparable to the general population (data not shown).

Only one third of the participants in our study were full time farmers. For these farmers the highest risk of chronic symptoms was found. As the majority of part time sheep breeders were not employed in occupations considered to put workers at high risk for asthma and chronic bronchitis, ${ }^{3}$ sheep breeding probably was the most relevant exposure.

A large number of animals was a major predictor of WRS. Unfortunately, due to concerns of the sheep breeders that the number of sheep reported in the survey might be given to the authorities, we were only able to include three categories for the number of sheep in our questionnaire. These categories might not be sufficient to differentiate the work intensity.

Additionally, the use of chemical footbaths emerged as a predictor for WRS and flu-like illness suggesting ODTS. Therefore, we have performed some preliminary measurements of endotoxin in sheep wool, indicating endotoxin content of 58.2-193.9 EU/mg wool. Thus, endotoxin exposure in sheep farmers during treatment of foot rot might be very high, and the use of chemical footbaths might be a proxy for exposure to endotoxins. Personal measurements of endotoxin exposure during the application of footbaths should be performed in sheep farmers. The chemicals used for footbaths were mainly formaldehyde $(20 \%)$ and copper sulphate $(18 \%)$. An association between the use of formaldehyde dip and breathing problems at work has recently been described by Kimbell-Dunn and colleagues. ${ }^{17}$

In conclusion, sheep breeders seem to be at high risk for the development of respiratory symptoms. This increased risk might be associated with work intensity as well as the use of chemicals. These results should be confirmed in a group of full time sheep farmers, including objective exposure measurements as well as clinical examinations.

\section{ACKNOWLEDGEMENTS}

The authors thank the sheep breeders for their participation. We are indebted to Robert Groerger for his support.

\section{Authors' affiliations \\ K Radon, C Winter, Institute of Occupational and Environmental Medicine, Ludwig-Maximilians-University, Munich, Germany}

This paper is part of the work of Christine Winter for her medical doctorate

\section{REFERENCES}

1 Radon K, Danuser B, Iversen $M$, et al. Respiratory symptoms in European animal farmers. Eur Respir J 2001;17:747-54.

2 American Thoracic Society, Schenker MB. Respiratory health hazards in agriculture. Am J Respir Crit Care Med 1998;158:S1-76.

3 Kogevinas M, Anto JM, Sunyer J, et al. Occupational asthma in Europe and other industrialised areas: a population-based study. European Community Respiratory Health Survey Study Group. Lancet 1999;353:1750-4.

4 Kimbell-Dunn M, Bradshaw L, Slater T, et al. Asthma and allergy in New Zealand farmers. Am J Ind Med 1999;35:51-7.

5 Von Essen SG, Scheppers LA, Robbins RA, et al. Respiratory tract inflammation in swine confinement workers studied using induced sputum and exhaled nitric oxide. J Toxicol Clin Toxicol 1998;36:557-65.

6 Donham KJ. Health effects from work in swine confinement buildings. Am J Ind Med 1990; 17:17-25

7 Vogelzang PF, van der Gulden JW, Folgering $\mathrm{H}$, et al. Organic dust toxic syndrome in swine confinement farming. Am J Ind Med 1999;35:332-4.

8 Vogelzang PF, van der Gulden JW, Folgering $\mathrm{H}$, et al. Endotoxin exposure as a major determinant of lung function decline in pig farmers. Am J Respir Crit Care Med 1998;157:15-18.

9 Vogelzang PF, van der Gulden JW, Preller L, et al. Bronchial hyperresponsiveness and exposure in pig farmers. Int Arch Occup Environ Health 1997;70:327-33.

10 Preller L, Heederik D, Boleij JS, et al. Lung function and chronic respiratory symptoms of pig farmers: focus on exposure to endotoxins and ammonia and use of disinfectants. Occup Environ Med 1995;52:654-60.

11 Radon K, Garz S, Schottky A, et al. Lung function and work-related exposure in pig farmers with respiratory symptoms. J Occup Environ Med 2000;42:814-20.

12 Mauny F, Polio JC, Monnet E, et al. Longitudinal study of respiratory health in dairy farmers: influence of artificial barn fodder drying. Eur Respir J 1997; 10:2522-8.

13 Dalphin JC, Dubiez A, Monnet E, et al. Prevalence of asthma and respiratory symptoms in dairy farmers in the French province of the Doubs. Am J Respir Crit Care Med 1998; 158(5 Pt 1):1493-8.

14 Radon K, Opravil U, Hartung J, et al. Work-related respiratory disorders and farming characteristics among cattle farmers in Northern Germany. Am J Ind Med 1999;36:444-9.

15 Radon K, Weber C, Iversen $M$, et al. Exposure assessment and lung function in pig and poultry farmers. Occup Environ Med 2001;58:405-10.

16 Donham KJ, Cumro D, Reynolds SJ, et al. Dose-response relationships between occupational aerosol exposures and cross-shift declines of lung function in poultry workers: recommendations for exposure limits. J Occup Environ Med 2000;42:260-9.

17 Kimbell-Dunn MR, Fishwick RD, Bradshaw L, et al. Work-related respiratory symptoms in New Zealand farmers. Am J Ind Med 2001;39:292-300.

18 Melbostad E, Eduard W, Magnus P. Chronic bronchitis in farmers. Scand J Work Environ Health 1997;23:271-80.

19 Magarolas R, Monso E, Aguilar X, et al. [Prevalence and risk factors of respiratory symptoms in farmers]. Med Clin (Barc) 2000;114:685-9.

20 Lyness EW, Pinnock DE, Cooper DJ, et al. Microbial ecology of sheep fleece. Proceedings of a workshop on Bacillus thuringiensis 1994;49:103-12.

21 Chin JC, Watts JE. Relationship between the immune response of sheep and the population dynamics of bacteria isolated from fleecerot lesions. Vet Microbiol 1992;32:63-74.

22 Rees H. Exposure to sheep dip and the incidence of acute symptoms in a group of Welsh sheep farmers. Occup Environ Med 1996;53:258-63.

23 Beach JR, Spurgeon A, Stephens R, et al. Abnormalities on neurological examination among sheep farmers exposed to organophosphorous pesticides. Occup Environ Med 1996;53:520-5.

24 Chyszewski MS. Evaluation of hoof moisture contents after foot bathing in the prevention of foot rot in sheep. Acta Academiae Agriculturae ac Technicae Olstenensis Veterinaria 1997;25:133-9.

25 Rylander R, Peterson Y, Donham KJ. Questionnaire evaluating organic dust exposure. Am J Ind Med 1990;17:121-6.

26 Zucchini W, Aguilar X. An introduction to model selection. J Math Psychol 2000;44:41-61.

27 Galobardes B, Sunyer J, Anto JM, et al. Effect of the method of administration, mail or telephone, on the validity and reliability of a respiratory health questionnaire. The Spanish Centers of the European Asthma Study. J Clin Epidemiol 1998;51:875-81.

28 Vogelzang PF, van der Gulden JW, Preller L, et al. Respiratory morbidity in relationship to farm characteristics in swine confinement work: possible preventive measures. Am J Ind Med 1996:30:212-18.

29 Kirkhorn SR, Garri VF. Agricultural lung diseases. Environ Health Perspect 2000;108:705-12.

30 Nowak D, Heinrich J, Jorres R, et al. Prevalence of respiratory symptoms, bronchial hyperresponsiveness and atopy among adults: west and east Germany. Eur Respir J 1996;9:2541-52. 